
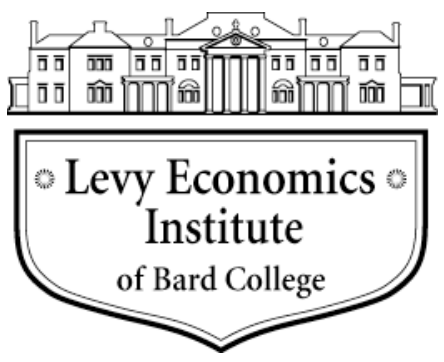

Working Paper No. 731

\title{
The Common Error of Common Sense: An Essential Rectification of the Accounting Approach \\ by
}

\author{
Egmont Kakarot-Handtke* \\ Institute of Economics and Law, University of Stuttgart
}

September 2012

* Correspondence: AXEC-Project, Egmont Kakarot-Handtke, Hohenzollernstraße 11, D-80801 Munich, Germany; e-mail: handtke@axec.de.

The Levy Economics Institute Working Paper Collection presents research in progress by Levy Institute scholars and conference participants. The purpose of the series is to disseminate ideas to and elicit comments from academics and professionals.

Levy Economics Institute of Bard College, founded in 1986, is a nonprofit, nonpartisan, independently funded research organization devoted to public service. Through scholarship and economic research it generates viable, effective public policy responses to important economic problems that profoundly affect the quality of life in the United States and abroad.

\author{
Levy Economics Institute \\ P.O. Box 5000 \\ Annandale-on-Hudson, NY 12504-5000 \\ http://www.levyinstitute.org
}

Copyright (C) Levy Economics Institute 2012 All rights reserved 


\begin{abstract}
This paper takes the explanatory superiority of the integrated monetary approach for granted. It will be demonstrated that the accounting approach could do even better, provided it frees itself from theoretically ill-founded notions like GDP and other artifacts of the equilibrium approach. National accounting as such does not provide a model of the economy but is, rather, the numerical reflex of the underlying theory. It is this theory that will be scrutinized, rectified, and ultimately replaced in what follows. The formal point of reference is "the integrated approach to credit, money, income, production and wealth" of Wynne Godley and Marc Lavoie.
\end{abstract}

Keywords: New Framework of Concepts; Structure-Centric; Axiom Set, Primacy of Theory; Income; Profit; Distributed Profit; Money; Flow; Residual; Transaction Matrix; General Complementarity

JEL Classifications: B41, E01 
In a comprehensive overview, Bezemer (2009) presented evidence that accounting or flow-of-fund macroeconomic models helped anticipate the credit crisis and economic recession. Juxtaposing the approaches of "accounting" versus "equilibrium" models helps to understand why "no one saw this coming" among users of equilibrium models, while some others using accounting models did. The present paper takes the explanatory superiority of the integrated monetary approach for granted. It will be demonstrated that the accounting approach could do even better provided it frees itself from theoretically ill-founded notions like GDP and other artifacts of the equilibrium approach. National accounting as such does not provide a model of the economy but is, in the ideal case, the unbiased numerical reflex of the underlying theory. It is this theory that will be scrutinized, rectified, and ultimately replaced in the following. The formal point of reference is "the integrated approach to credit, money, income, production and wealth" of Godley and Lavoie (2007). It is common ground that there is no such thing as a dividing line between "economics" and "accounting." Economic theory and national accounting must fit like hand and glove.

The accounting approach is not simply about gathering market transaction data and interpreting them. There can be no production and income accounts without a prior theory of factor remuneration and profit.

Since, therefore, it is vain to hope that truth can be arrived at, either in Political Economy or in any other department of the social science, while we look at the facts in the concrete, clothed in all the complexity with which nature has surrounded them, and endeavor to elicit a general law by a process of induction from a comparison of details; there remains no other method than the à priori one, or that of "abstract speculation." (Mill 2004, pp. 113-114)

That is, one has to leap from commonplace economics which trades in easy to grasp phenomena on a small scale to an extremely abstract set of foundational propositions about the economy as a whole. Theories have a logical architecture consisting of premises and conclusions or, in a purely formal context, of axioms and theorems. Each theory starts from a small set of foundational "hypotheses or axioms or postulates or assumptions or even principles" (Schumpeter 1994, p. 15). It is not an indispensable necessity that the foundational propositions of a theory be formalized, but it is a good idea.

Formalization is a way of setting off from the forest of implicit assumptions and the surrounding thickness of confusion, the ground that is required for the theory being considered. ... In areas of science where great controversy exists about even the most 
elementary concepts, the value of such formalization can be substantial.(Suppes 1968, pp. 654-655)

Formalization per se, though, is not sufficient. General equilibrium theory is formalized but rests on a set of behavioral axioms (Arrow and Hahn 1991, p. v). It is not always recognized that this approach has been abandoned by its most outstanding proponents.

It is good to have [the technically best study of equilibria], but perhaps the time has now come to see whether it can serve in an analysis of how economies behave. The most intellectually exciting question of our subject remains: is it true that the pursuit of private interest produces not chaos but coherence, and if so, how is it done? (Hahn, 1984, p. 102)

The problem is that there is no convincing alternative.

There is no statement which characterizes how post-Keynesian theory can underlie the way in which an industrial capitalist economy works as an organic whole. (Godley and Lavoie 2007, p. 3), original emphasis.

Therefore, the accustomed formal points of departure are in the present paper replaced by structural axioms. By choosing objective structural relationships as axioms the familiar behavioral hypotheses are not ruled out but are provisionally relegated to the periphery. Structural axiomatization provides the correct profit theory. This, in turn, is the prior condition for the explanation of how the monetary economy works.

The economic elements and their logical relations are set up in Section 0. The shortest possible description of the most elementary economic configuration includes money, credit, debt, profit, distributed profit, and the market clearing price at any level of employment. The distinction of profit and distributed profit is crucial. Raw transaction recording makes this distinction and the economic implication visible in the accounting matrix. Cooked transaction recording produces the spurious equality of valued output and income. In Section 2 the analysis is extended to the investment economy. It is shown that the IS equality/identity cannot be derived in a formally acceptable way from national accounting. Section 3 concludes. 


\section{THE ECONOMIC ELEMENTS AND THEIR LOGICAL RELATIONS}

\subsection{Structural Axioms}

The first three structural axioms relate to income, production, and expenditures in a period of arbitrary length. The period length is conveniently assumed to be the calendar year. Simplicity demands that we have for the beginning one world economy, one firm, and one product. All quantitative and temporal extensions have to be deferred until the implications of the most elementary economic configuration are perfectly transparent. Axiomatization is about ascertaining the minimum number of premises. Three suffice for the beginning.

Total income of the household sector $Y$ in period $t$ is the sum of wage income, i.e. the product of wage rate $W$ and working hours $L$, and distributed profit, i.e. the product of dividend $D$ and the number of shares $N$.

$$
Y=W L+D N \quad \mid t
$$

Output of the business sector $O$ is the product of productivity $R$ and working hours.

$$
O=R L \quad \mid t
$$

Consumption expenditures $C$ of the household sector is the product of price $P$ and quantity bought $X$.

$$
C=P X \quad \mid t
$$

The axioms represent the pure consumption economy, that is, no investment expenditures, no foreign trade, and no taxes or any other activity of the government sector. All axiomatic variables are measurable in principle. No nonempirical concepts like utility, equilibrium, rationality, decreasing returns, or perfect competition are put into the premises.

The economic meaning is rather obvious for the set of structural axioms. What deserves mention is that total income in (1) is the sum of wage income and distributed profit and not of wage income and profit. Profit as defined with (7), and distributed profit as given with (1), are quite different things.

\subsection{Definitions}

Definitions are supplemented by connecting variables on the right-hand side of the identity sign that have already been introduced by the axioms. With (4) wage income $Y_{W}$ and distributed profit 
$Y_{D}$ is defined:

$$
Y_{W} \equiv W L \quad Y_{D} \equiv D N \quad \mid t .
$$

Definitions add no new content to the set of axioms but determine the logical context of concepts. New variables are introduced with new axioms.

We define the sales ratio as:

$$
\rho_{X} \equiv \frac{X}{O} \mid t
$$

A sales ratio $\rho_{X}=1$ indicates that the quantity sold $X$ and the quantity produced $O$ are equal or, in other words, that the product market is cleared.

We define the expenditure ratio as:

$$
\rho_{E} \equiv \frac{C}{Y} \mid t
$$

An expenditure ratio $\rho_{E}=1$ indicates that consumption expenditures $C$ are equal to total income $Y$, in other words, that the household sector's budget is balanced.

\subsection{Profit}

The business sector's financial profit in period $t$ is defined with (7) as the difference between the sales revenues, or the economy as a whole identical with consumption expenditure $C$, and costs, here identical with wage income $Y_{W}:^{1}$

$$
\Delta Q_{f i} \equiv C-Y_{W} \quad \text { with } \quad \rho_{X}=1 \quad \mid t .
$$

In explicit form, after the substitution of (3) and (4), this definition is identical with that of the theory of the firm:

$$
\Delta Q_{f i} \equiv P X-W L \quad \mid t .
$$

\footnotetext{
${ }^{1}$ Profits from changes in the value of nonfinancial assets are neglected here, i.e. the condition of market clearing $\rho_{x}=1$ holds throughout. For details about changes of inventory see Kakarot-Handtke 2011b, pp. 2-11. Nonfinancial profit is treated at length in Kakarot-Handtke 2011a.
} 
By inserting the first axiom (1) and the definitions (4) into (7) one gets:

$$
\Delta Q_{f i} \equiv C-Y+Y_{D} \mid t
$$

The three definitions are formally equivalent, that is, profit can be looked at under three different perspectives that together render the whole picture. Eq. (9) shows the relation between profit $\Delta Q_{f i}$ and distributed profit $Y_{D}$ which is invisible in (7) or (8).

\subsection{The Primacy of Theory}

If distributed profit $Y_{D}$ is set to zero in the 1st axiom (1) then $Y=Y_{W}$ and profit or loss of the business sector $\Delta Q_{f i}$ is determined as shown in Figure 1.

Figure 1: The Emergence of Financial Profit $\Delta Q_{f i}$ in the Simplest Case, i.e. $Y_{D}=0$ and $\rho_{X}=1$

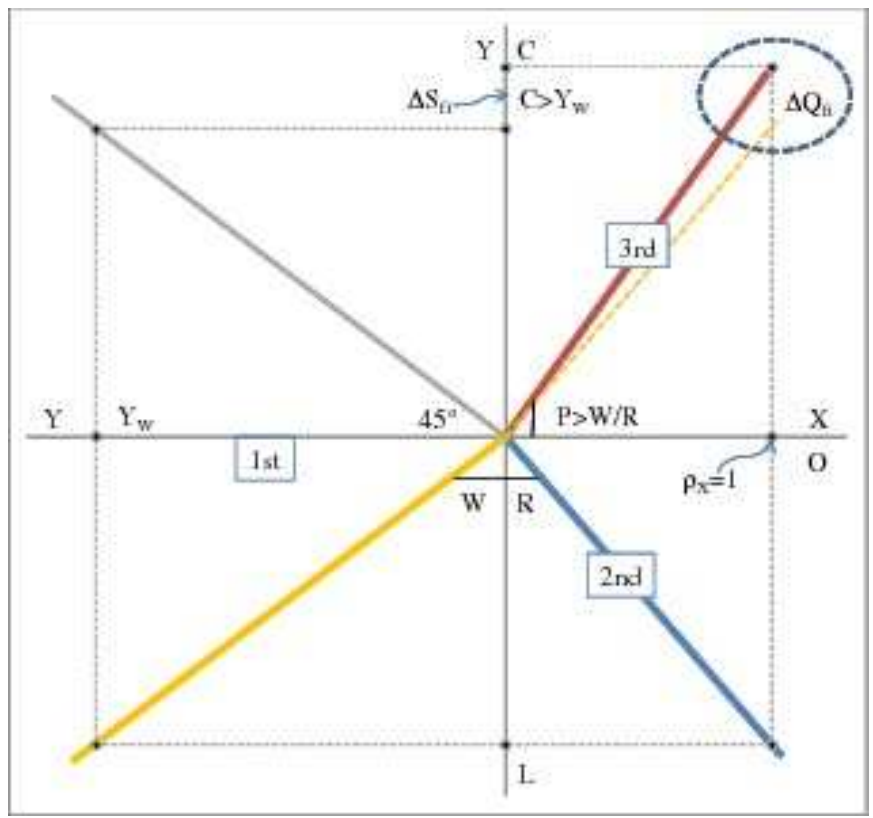

The four quadrant positive rational diagram, $4 Q P R$-diagram for short, makes the simplified consumption economy immediately comprehensible. The four axes represent the positive rational values of the variables employment $L$, income $Y$, consumption expenditures $C$, quantity bought 
$X$, and output $O$, respectively. The bisecting line in the northwestern quadrant mirrors income from the horizontal to the vertical axis. The quadrants are numbered according to the axioms they enclose.

In the 1st quadrant total income $Y$ is given as product of wage rate $W$ and working hours $L$ because distributed profit has been set to zero in (1), hence $Y=Y_{W}$. The wage rate is equal to the tangent function of the ray's angle at $L=1$.

In the 2nd quadrant output $O$ is given as product of productivity $R$ and working hours $L$. The productivity is determined by the underlying production process and may vary with labor input. The ray from the origin that represents the 2 nd axiom (2) should therefore not be interpreted as a linear production function. The 2 nd axiom can track any production function.

In the 3rd quadrant consumption expenditures $C$ is given as product of price $P$ and quantity bought $X$.

The condition of market clearing makes that the price now becomes the dependent variable. From (3) and (6) follows:

$$
P^{\star}=\rho_{E} \frac{W}{R} \quad \text { if } \quad \rho_{X}=1 ; Y_{D}=0 \quad \mid t .
$$

The market clearing price $P^{\star}$ is higher than unit wage costs $\frac{W}{R}$ if the expenditure ratio $\rho_{E}$ is greater than unity. The profit per unit is positive. This is what the firm sees; the firm cannot see that the market clearing price is above unit wage costs because the expenditure ratio is above unity. Profit is given by the equivalent equations (7) to (9). For the business sector as a whole to make a profit consumption expenditure $C$ has in the simplest case, i.e. $Y_{D}=0$, to be greater than wage income $Y_{W}$. So that profit comes into existence in the pure consumption economy the household sector must run a deficit at least in one period. This in turn makes the inclusion of the financial sector mandatory. A theory that does not include at least one bank that supports the concomitant credit expansion cannot capture the essential features of the market economy. ${ }^{2}$

\footnotetext{
${ }^{2}$ If the purchase of all long-lived consumption goods, e.g. houses, is correctly subsumed under consumption expenditures, (see Godley and Lavoie 2007, p. 36), there arises no practical problem with regard to collateral for the banking industry and a sound credit expansion may proceed, in principle, for an indefinite time span in the pure consumption economy.
} 


\subsection{The Complementarity of Dissaving and Profit}

Consumption expenditure $C$ in Figure 1 is higher than income $Y \quad\left(=Y_{W}\right.$ at the moment according to (1) and $Y_{D}=0$ ), that is, the households dissave. Financial saving respectively dissaving is defined as: ${ }^{3}$

$$
\Delta S_{f i} \equiv Y-C \quad \mid t
$$

In the period under consideration the household sector's budget is not balanced. An alternative form of stating that the household sector dissaves is $\rho_{E}>1$ or vice versa in the case of saving $\rho_{E}<1$

For easy comparison the definitions of profit (7) and saving (11) are juxtaposed:

$$
\begin{aligned}
& \Delta Q_{f i} \equiv C-Y_{W} \\
& \Delta S_{f i} \equiv Y_{W}-C \quad \text { if } \quad Y_{D}=0 \\
& ------- \\
& \Delta Q_{f i} \equiv-\Delta S_{f i}
\end{aligned}
$$

The complementarity of the definitions makes that profit is equal to dissaving and loss is equal to saving. Profit for the business sector as a whole has nothing to do with productivity or efficiency. Different productivities, wage rates, or employment levels, which are embodied in (8), play a role when it comes to the distribution of financial profit $\Delta Q_{f i}$ among the firms that compose the business sector. The individual firms cannot see that dissaving of the household sector is, according to (12), the ultimate source of profit in the pure consumption economy. Metaphorical, the agents are chained in Plato's Cave and try to make sense of proximate phenomena.

\subsection{Commonsensical Since Adam Smith}

The model of Figure 1 consists of the structural axiom set and two conditions, i.e $Y_{D}=0$ and $\rho_{X}=1$. The implications of the simplest and therefore most transparent of all economic configurations can be summarized as follows:

- In order that profit comes into existence for the first time in the pure consumption economy the household sector must run a deficit at least in one period.

\footnotetext{
${ }^{3}$ For the treatment of nonfinancial saving see Kakarot-Handtke 2011a, pp. 8-12.
} 
- The business sector's revenues can only be greater than costs if, in the simplest of all possible cases, consumption expenditures are greater than wage income.

- Wage income is the factor remuneration of labor input $L$. Profit $\Delta Q_{f i}$ is not a factor income. Since capital is non-existent in the pure consumption economy profit is not functionally attributable to capital.

- Profit has no real counterpart in the form of a piece of the output cake. Profit has a monetary counterpart.

- The existence and magnitude of financial profit does not depend on profit maximizing behavior but solely on the expenditure ratio.

- The value of output is, in the general case, different from the sum of factor incomes. This is the defining property of the monetary economy.

- Only in the limiting case $Y_{D}=0, \rho_{X}=1$ and $\rho_{E}=1$ is the value of output equal to factor income, i.e. $C=Y_{W}$. This is the zero profit case.

Figure 1 says in plain words: the value of output is greater than factor income. The fundamental error of value theory is to start from the premise that the value of the output of goods and services is always equal to the sum of factor incomes (Godley and Lavoie 2007, p. 4). This error can be traced back to the early and rude state of theoretical economics.

... the whole price of that annual produce, naturally divides itself ... into three parts; the rent of land, the wages of labour, and the profits of stock. (Smith 2008, p. 155)

Ricardo sharpened Smith's intuition to the cake-theory of distribution.

Ricardo's theory of wages is very simple: Whatever raises the wages of labor lowers the profits of stock. In other words, wages can only rise at the expense of profits or vice versa. ... "The whole thing is so evident that it is almost a truism. A cake is being shared between two persons. If one gets more than his due share is it not evident that the other must get less?" Gide and Rist, quoted in (Redman 1997, p. 280)

J. S. Mill had no friendly word for the truisms of common sense.

People fancied they saw the sun rise and set, the stars revolve in circles round the pole. We now know that they saw no such thing; what they really saw was a set of appearances, equally reconcileable with the theory they held and with a totally different one. It seems strange that such an instance as this, ..., should not have opened the eyes of the bigots of common sense, and inspired them with a more modest distrust 
of the competency of mere ignorance to judge the conclusions of cultivated thought. (Mill 2006, p. 783), original emphasis

Apart from being presumptuous, common sense is simply not up to the task. Keynes, too, had no clear idea of the fundamental economic concepts income and profit. He wrestled long to solve the profit puzzle but in the end he gave up and took his inspiration from 'the practices of the Income Tax Commissioners' (Coates 2007, p. 90).

Thus the factor cost and the entrepreneur's profit make up, between them, what we shall define as the total income resulting from the employment given by the entrepreneur. (Keynes 1973, p. 23), original emphasis

Adam Smith's misleading intuition finally made it into the textbooks.

$G D P$, or gross domestic product, can be measured in two different ways: (1) as the flow of final products, or (2) as the total costs or earnings of inputs producing output. Because profit is a residual, both approaches will yield exactly the same total GDP. (Samuelson and Nordhaus 1998, p. 392)

This quote is paradigmatic for the flimsy logic and the loose verbal reasoning that is endemic in economics. ${ }^{4}$ Costs, earnings, and residuals are not the same thing. Figure 1 shows, and the underlying formalism proves, that neither the classical, nor the neoclassical, nor the Keynesian school came to grips with income and profit (Desai 2008), (Tómasson and Bezemer 2010).

To clarify the matter, we have to turn to the facts in the concrete. And this is where the accounting approach comes in as the final arbiter.

\subsection{Raw Transaction Recording}

The first task of (global or national) accounting is to record all market transaction in the pure consumption economy as they occur during a given period. This is a machine-like operation, the interpretation of the resulting numbers is a quite different matter. At this stage it is only important that nothing gets lost and nothing is added.

Figure 1 comprises two entities: the household sector $\mathcal{E}_{\mathbf{H}}$ and the business sector $\mathcal{E}_{\mathbf{B}}$. The nominal market transactions between the sectors are summarized for easy comparison with

\footnotetext{
4 "I often wonder whether other subjects suffer as much from textbook writers" (Hahn 1980, p. 127). See also Dennis 1982.
} 
exemplary numbers in Figure 2. The $\dashv$-sign indicates that the numbers in the respective column and row sum up to zero. This is a trivial property of the transaction matrix. ${ }^{5}$

Figure 2: Raw Transaction Recording in the Pure Consumption Economy (the balancing row $\Delta$ does not represent a market transaction)

\begin{tabular}{|} 
Balancing of the transaction matrix & $\mathcal{E}_{\mathbf{H}}$ & $\mathcal{E}_{\mathbf{B}}$ & $\Sigma$ \\
\hline Consumption expenditure & $C$ & -100 & 100 & 0 \\
\hline Wage income & $Y_{W}$ & 80 & -80 & 0 \\
\hline Balancing items & $\Delta$ & -20 & 20 & -1 \\
& & $\Delta S_{f i}$ & $\Delta Q_{f i}$ & \\
\hline
\end{tabular}

Compared to Figure 1 the transaction matrix shows only the nominal aspect of the pure consumption economy and involves a noticeable loss of information. Employment, price, and productivity, among other important variables, are no longer available. Therefore, the accounting matrix cannot provide a basis for theoretical economics. The model of Figure 1 explains the matrix of Figure 2 and not the other way round. The accounting matrix has no explanatory power of its own, it is always derivative.

The balancing items (dis)saving $\Delta S_{f i}$ and profit $\Delta Q_{f i}$ do not represent a market transaction. If we have the residual of one sector we can, due to the formal logic of the matrix, accurately "predict" the other. The causal arrow, which cannot be read off the matrix, runs from saving-dissaving to loss-profit. The nominal residuals reproduce (12) and point to the monetary side.

\footnotetext{
5 "Our method is rooted in the fact that every transaction by one sector implies an equivalent transaction by another sector ..., while every financial balance ... must give rise to an equivalent change in the sum of its balance-sheet (or) stock variables, ..." (Godley and Lavoie 2007, p. xxxiv).
} 


\subsection{Money}

If income is higher than consumption expenditure the household sector's stock of money increases. The change in period $t$ is defined as:

$$
\Delta \bar{M}_{\mathbf{H}} \equiv^{m} Y-C \quad \mid t .
$$

The identity sign's superscript $m$ indicates that the definition refers to the monetary sphere. The juxtaposition of the monetary (13) and the nominal (11) sphere yields:

$$
\begin{aligned}
& \Delta \bar{M}_{\mathbf{H}} \equiv^{m} Y-C \\
& \Delta S_{f i} \equiv Y-C \\
& -------- \\
& \Delta \bar{M}_{\mathbf{H}} \equiv^{m} \Delta S_{f i .}
\end{aligned}
$$

Financial saving-dissaving corresponds exactly to a change of the household sector's stock of money in period $t$; we have two appearances of the same difference of flows. This special variant of what is in the strict formal sense a tautology, here indicated by the superscript ${ }^{m}$, is characteristic of double-entry accounting.

The stock of money $\bar{M}_{H}$ at the end of an arbitrary number of periods is defined as the numerical integral of the previous changes of the stock plus the initial endowment:

$$
\bar{M}_{\mathbf{H} \bar{t}} \equiv \sum_{t=1}^{t} \Delta \bar{M}_{\mathbf{H} t}+\bar{M}_{\mathbf{H} 0}
$$

The changes in the stock of money as seen from the business sector are symmetrical to those of the household sector:

$$
\Delta \bar{M}_{\mathbf{B}} \equiv^{m} C-Y \quad \mid t .
$$

The juxtaposition of the monetary (16) and the nominal (7) sphere yields:

$$
\begin{aligned}
& \Delta \bar{M}_{\mathbf{B}} \equiv^{m} C-Y \\
& \Delta Q_{f i} \equiv C-Y \text { if } Y=Y_{W} \\
& ------- \\
& \Delta \bar{M}_{\mathbf{B}} \equiv^{m} \Delta Q_{f i} .
\end{aligned}
$$

Financial profit-loss corresponds exactly to a change of the business sector's stock of money in period $t$. 
The business sector's stock of money at the end of an arbitrary number of periods is accordingly given by:

$$
\bar{M}_{\mathbf{B} \bar{t}} \equiv \sum_{t=1}^{t} \Delta \bar{M}_{\mathbf{B} t}+\bar{M}_{\mathbf{B} 0}
$$

In order to reduce the monetary phenomena to the essentials it is supposed that all financial transactions are carried out by the central bank. The stock of money then takes the form of current deposits or current overdrafts. Initial endowments can be set to zero. Then, if the household sector owns current deposits according to (15) the current overdrafts of the business sector are of equal amount according to (18), and vice versa. As it happens, each sector's stock of money is either positive (= deposits) or negative (= overdrafts). Money, i.e. deposits at the central bank, and credit are at first symmetrical as shown in Figure 3.

Figure 3: Household and Business Sector's Accounts at the Central Bank with Market Transactions Corresponding to Figure 2

\begin{tabular}{|r|r|r|r|}
\hline \multicolumn{2}{|c|}{$\mathcal{E}_{\mathbf{H}}$} & \multicolumn{2}{c|}{$\mathcal{E}_{\mathbf{B}}$} \\
\hline payments & receipts & payment & receipts \\
\hline-100 & 80 & -80 & 100 \\
\hline-20 & & & 20 \\
change of & & & change of \\
overdrafts & & & $\Delta \bar{M}_{\mathbf{B}}$ \\
$\Delta \bar{M}_{\mathbf{H}}$ & & & \\
\cline { 1 - 2 } & & &
\end{tabular}

From the central bank's perspective the quantity of money at the end of an arbitrary number of periods is then given by the absolute value either from (15) or (18):

$$
\bar{M}_{\bar{t}} \equiv\left|\sum_{t=1}^{t} \Delta \bar{M}_{\mathbf{H} t ; \mathbf{B} t}\right| \quad \text { if } \quad \bar{M}_{\mathbf{H} 0 ; \mathbf{B} 0}=0 .
$$


The quantity of money is always $\geq 0$ and follows directly from the axioms. It is assumed at first that the central bank plays an accommodative role and simply supports the autonomous market transactions between the household and the business sector. For the time being, the quantity of money is the dependent variable. Money is not given but created by the household and business sector's transactions. To the balancing row of Figure 2 corresponds the simple flow-of-funds matrix of Figure 3.

\subsection{Cooked Transaction Recording}

We take up Figure 2 with the raw recordings of period $t$. The accountant now adds two rows (GDP (memo) and Net profits) and one column (Capital). Figure 4 is the simplified version of Fig. 2.5. from (Godley and Lavoie 2007, p. 37) with Government omitted.

Figure 4: Cooked Transaction Recording of the Simplest Case of the Pure Consumption Economy (compares to Figure 2)

\begin{tabular}{|c|r|r|r|r|r|}
\cline { 3 - 6 } \multicolumn{2}{l|}{} & $\mathcal{E}_{\mathbf{H}}$ & $\mathcal{E}_{\mathbf{B}}$ & Capital & \multicolumn{1}{|c|}{} \\
\hline Consumption expenditure & $C$ & -100 & 100 & & 0 \\
\hline [GDP (memo)] & & & $\Upsilon$ & & \\
\hline Wage income & $Y_{W}$ & 80 & -80 & & 0 \\
\hline Net profits & & & -20 & 20 & 0 \\
\hline Balancing items & $\Delta$ & -20 & 0 & 20 & 0 \\
& & $S A V_{h}$ & & $F U$ & \\
\hline
\end{tabular}

The comparison with the original Figure 2 shows that the residual profit $\Delta Q_{f i}$ has been taken out of the Balancing item row and placed among the market transactions. The shift from the row Balancing items to Net profits involves a fictive entry in the column $\mathcal{E}_{\mathbf{B}}$ and the column Capital. 
This imputed entry conforms to the rules; the row and column sum of the matrix is still zero. Therefore, the accountant's entry cannot be rejected on formal grounds.

As a result we arrive in column $\mathcal{E}_{\mathbf{B}}$ at the pivotal GDP relation (Godley and Lavoie 2007, p. 34) eq. (2.1):

$$
\begin{gathered}
\Upsilon=C+\underbrace{I+G}_{0}=W B+F+\underbrace{I N T+T}_{0} \\
\text { with } \\
W B \rightarrow Y_{W} \quad F \rightarrow \Delta Q_{f i} \\
\quad \text { simplified } \\
\Upsilon=C=Y_{W}+\Delta Q_{f i}
\end{gathered}
$$

Column $\mathcal{E}_{\mathbf{B}}$ and eq. (20) yield the expenditure and income components of gross domestic product $\Upsilon$. The cooked matrix states in plain words: the value of gross domestic product $\Upsilon$ is equal to (a) the sum of all expenditures on goods and services, here $C$, and (b), the sum of incomes paid for production, here wages $Y_{W}$ and profits $\Delta Q_{f i}$. This formula has to be rejected because wage income and profit do not fit into the same category:

- $Y_{W}$ is a market transaction, $\Delta Q_{f i}$ is a residual of market transactions,

- $Y_{W}$ reduces the business sector's stock of money at the central bank, $\Delta Q_{f i}$ does not,

- $Y_{W}$ is a cost item for the the business sector, $\Delta Q_{f i}$ is not,

- $Y_{W}$ is a factor remuneration, $\Delta Q_{f i}$ is not.

Eq. (20) implies a semantic inconsistency or category mistake. The accountant's imputed transaction in row 4 is illegitimate. Profit cannot be put on the same footing with wage income, both magnitudes are incommensurable. By consequence, GDP is never equal to factor income. Eq. (20) is derived from the accounting matrix and has no sound theoretical foundation. Accounting without theory is pointless. Theory without structural axiomatic foundations is insufficient. There is no way around it: the common sense from Adam Smith to the accounting conventions of the UN's System of National Accounts (2009, p. 34) has to be rejected. There cannot be a majority vote on this matter.

\subsection{Profit Distribution, Retained Profit, and Saving}

The process of profit origination and distribution is logically split up and analyzed in two separate 
steps. We have dealt with the first-time emergence of profit in Section 0. In the next period, the business sector can distribute profit to the household sector or keep it in the business sector. With distributed profit $Y_{D}>0$ and the conditions of market clearing $\rho_{X}=1$ the pure consumption economy now looks as shown in Figure 5.

Figure 5: Market clearing price $P^{\star}$ and financial profit $\Delta Q_{f i}$ under the conditions $Y_{D}>0$, $\rho_{E}>1$ and $\rho_{X}=1$

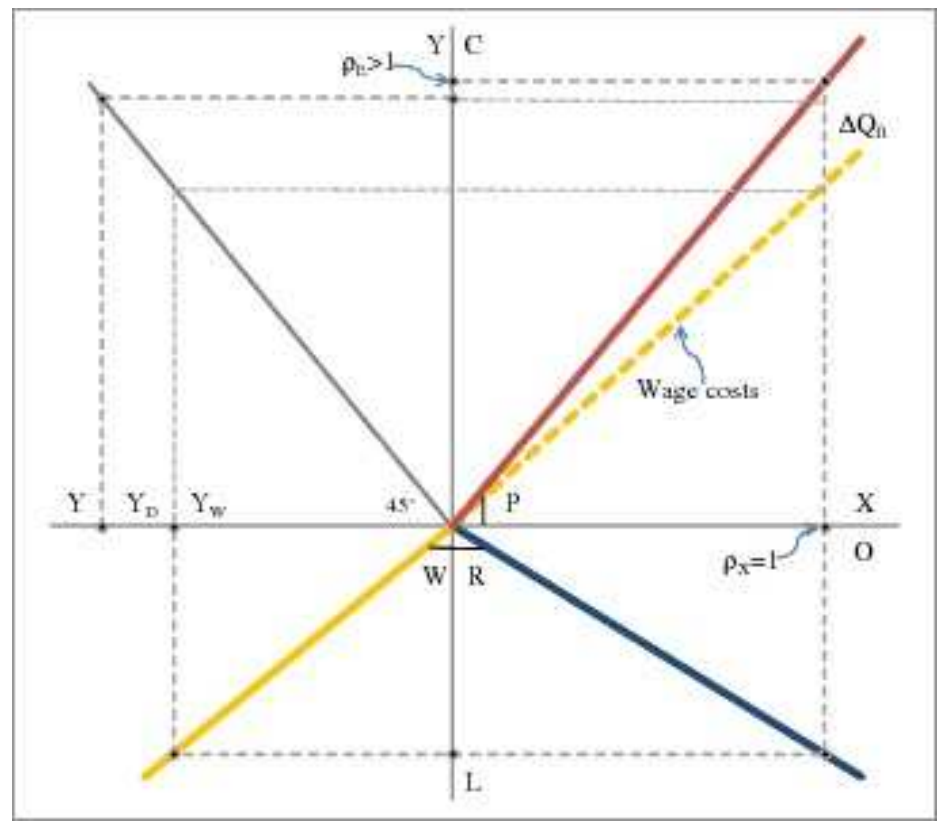

The market clearing price follows from (3), (4) and (1) as:

$$
P^{\star}=\rho_{E}\left(\frac{W}{R}+\frac{Y_{D}}{R L}\right) \quad \text { if } \quad \rho_{X}=1 \quad \mid t .
$$

The market clearing price $P^{\star}$ is higher than unit wage costs $\frac{W}{R}$ if the expenditure ratio is greater than unity or distributed profit is greater than zero, or both. Given the amount of distributed profit $Y_{D}$ as well as wage rate $W$ and productivity $R$ the price varies with employment $L$. With increasing employment the market clearing price falls. 
Due to the interdependence of markets, the market clearing price in the product market $P^{\star}$ depends inter alia on the current wage rate $W$ in the labor market. Whether the economy is at full employment or not is a matter of indifference. All variations of employment, wage rate, productivity, or distributed profit are transformed via (21) into a new market clearing price. Profit is given with (9).

If nothing is distributed, then profit adds entirely to the financial wealth of the firm. Retained profit $\Delta Q_{r e}$ is defined for the business sector as a whole as the difference between profit and distributed profit in period $t$ :

$$
\Delta Q_{r e} \equiv \Delta Q_{f i}-Y_{D} \Rightarrow \Delta Q_{r e} \equiv C-Y \quad \mid t .
$$

Retained profit is, due to (9), equal to the difference of consumption expenditure $C$ and total income $Y$.

Financial saving is given by (11) as the difference of income and consumption expenditure. In combination with (22) follows:

$$
\begin{gathered}
\Delta Q_{r e} \equiv C-Y \\
\Delta S_{f i} \equiv Y-C \\
------- \\
\Delta Q_{r e} \equiv-\Delta S_{f i}
\end{gathered}
$$

Financial saving and retained profit always move in opposite directions. Let us call this the Special Complementarity; it asserts that the complementary notion to saving is not investment but negative retained profit. Positive retained profit is the complementary of dissaving.

If household sector saving $\Delta S_{f i}$ happens to be zero then retained profit is also zero. This entails that profit $\Delta Q_{f i}$ and distributed profit $Y_{D}$ are equal in the period under consideration. It should be obvious that this never happens in the real world. It happens, though, by formal implication in equilibrium models.

There is no need to assume that all profits are distributed to households as is invariably assumed, without question, in mainstream macroeconomics. (Godley and Lavoie 2007, p. 35), original emphasis.

As a matter of fact, nothing more is needed to render a macroeconomic model worthless. The equality of profit and distributed profit is a convenient criterion for rapid and safe debunking. In 
the real world, we always have $\Delta S_{f i} \neq 0$ and therefore $\Delta Q_{f i} \neq Y_{D}$ according to (23). Let us call this reality's signifier.

\subsection{The Black Hole Effect}

The rule enforcing that all columns, each representing a sector, must sum to zero as well is particularly interesting because it has a well-defined economic meaning. The zero sum rule for each column represents the budget constraint of each sector. ... Without this armature, accounting errors may pass unnoticed and unacceptable implications may be ignored. With this framework, 'there are no black holes.' ... (Godley and Lavoie 2007, p. 35)

In view of endemic looseness in the economic discourse this is, no doubt, the chief merit of the accounting approach. The formal and semantic integrity, however, is only secured in the case of raw transaction recording. Figure 6 is the faithful accounting counterpart of Figure 5 which displays the general interrelation of profit and distributed profit in the pure consumption economy.

Figure 6: Raw Transaction Recording of Profit Distribution and Balancing in Accordance with the Special Complementarity (23)

\begin{tabular}{|} 
Balancing of the transaction matrix & $\mathcal{E}_{\mathbf{H}}$ & $\mathcal{E}_{\mathbf{B}}$ & $\Sigma$ \\
\hline Consumption expenditure & \multicolumn{1}{|c|}{$C$} & -100 & 100 & 0 \\
\hline Wage income & $Y_{W}$ & 80 & -80 & 0 \\
\hline Distributed profit & $Y_{D}$ & 15 & & 15 \\
\hline Balancing items & $\Delta_{1}$ & -5 & 20 & \\
\hline Distributed profit & $Y_{D}$ & & -15 & -15 \\
\hline Balancing items & $\Delta_{2}$ & -5 & 5 & $\dashv$ \\
& & & & \\
\hline & & $\Delta S_{f i}$ & $\Delta Q_{r e}$ & \\
\hline
\end{tabular}


Column $\mathcal{E}_{\mathbf{B}}$ shows the interrelation of financial profit $\Delta Q_{f i}$, distributed profit $Y_{D}$ and retained profit $\Delta Q_{r e}$. The balancing row $\Delta_{2}$ reproduces the Special Complementarity (23). The matrix sums up to zero and in the final analysis retained profit is causally determined by saving. Things are different with the cooked transactions in Figure 7. Although profit distribution is a transaction between the business and the household sector it does not appear in the $\mathcal{E}_{\mathbf{B}}$ column. The proper place for distributed profit is already occupied by profit which, as we know from Figure 4 , is a residual that the accountant has taken from the balancing items and placed among transactions.

Figure 7: Cooked Transaction Recording of Profit and Distributed Profit (compares to Figure 6 and Figure 4)

\begin{tabular}{|c|r|r|r|r|r|}
\cline { 3 - 6 } \multicolumn{2}{l|}{} & $\mathcal{E}_{\mathbf{H}}$ & $\mathcal{E}_{\mathbf{B}}$ & Capital & \multicolumn{1}{c|}{} \\
\hline Consumption expenditure & $C$ & -100 & 100 & & 0 \\
\hline [GDP (memo)] & & & $\Upsilon$ & & \\
\hline Wage income & $Y_{W}$ & 80 & -80 & & 0 \\
\hline Net profits & & 15 & -20 & 5 & 0 \\
\hline Balancing items & $\Delta_{1}$ & -5 & 0 & 5 & 0 \\
& & $S A V_{h}$ & & $F U$ & \\
\hline
\end{tabular}

The pivotal GDP relation in column $\mathcal{E}_{\mathbf{B}}$ is exactly equal to Figure 4 and eq. (20). The cooked transaction recording renders the same results for different underlying economic situations. That is to say, the crucial information about profit distribution, that makes a real world difference, disappears without a trace in the GDP column of Figure 7. This is the black hole effect of GDP accounting. This effect would not make much of a difference if profit and distributed profit were equal in period $t$. Since this never happens in the real world the GDP accounting of Figure 7 is definitively misleading. The first consequence for the accounting approach is therefore to part with the notion of GDP and the implicit equality of valued output and factor income. 


\section{THE INVESTMENT ECONOMY}

\subsection{The General Complementarity}

Having clarified the formal properties of the pure consumption economy we are now in the position to include investment expenditure. Based on the differentiated structural axiom set, it is assumed that the investment good producing firm $\mathcal{E}_{\mathbf{B} I}$ produces $O_{I}=X_{I}$ units which are bought by the consumption good producing firm $\mathcal{E}_{\mathbf{B} C}$ to be used for the production of consumption goods in future periods. The households buy the output of the consumption good producing firm, for details see Kakarot-Handtke 2011c. From (7) then follows the financial profit of each firm:

$$
\begin{aligned}
\Delta Q_{f i C} & \equiv C-Y_{W C} \\
\Delta Q_{f i I} & \equiv I-Y_{W I}
\end{aligned}
$$

Total financial profit, defined as the sum of both firms, is then given by the sum of consumption expenditure and investment expenditure minus wage income which is here expressed, using (1), as the difference of total income minus distributed profit:

$$
\Delta Q_{f i} \equiv C+I-\left(Y-Y_{D}\right) \text { with } \quad Y_{W} \equiv Y_{W C}+Y_{W I} \mid t .
$$

From this and the definition of financial saving (11) follows:

$$
\Delta Q_{f i} \equiv I-\Delta S_{f i}+Y_{D} \quad \mid t
$$

Higher total financial profits on the one side demand as a corollary, i.e. as a logical implication of the definition itself, higher investment expenditures or distributed profits or lower saving on the other side. By finally applying the definition of retained profit (22) the General Complementarity follows: ${ }^{6}$

$$
\Delta Q_{r e} \equiv I-\Delta S_{f i} \mid t
$$

6 This equation is not entirely new, see Robinson 1956, p. 402, Lavoie 1992, p. 159 eq. (4.3), Allais 1993, p. 69, and Godley and Lavoie 2007, p. 37 fn. 9. But only Allais clearly stated the implications: “Autrement dit l'investissement n’est pas égal à l'épargne spontanée, mais à l'épargne spontanée augmenté du revenue non distribué des entreprises ..." Roughly: "In other words, investment expenditure is not equal to spontaneous saving but to spontaneous saving augmented by the business sector's retained profit ..." This, though, made not much impact on the other side of the language barrier. 
If retained profit $\Delta Q_{r e}$ is zero, that is, if profit $\Delta Q_{f i}$ and distributed profit $Y_{D}$ happen to be equal, in (22), then, as a corollary, investment expenditure and household saving in (27) must be equal, too. Vice versa, if it happens that household saving is equal to investment expenditure then, as a corollary, profit and distributed profit must be equal too. In reality, though, profit and distributed profit are never equal and correspondingly household sector saving $\Delta S_{f i}$ and business sector investment $I$ are not equal either. The fact that retained profit is different from zero in the real world can be taken as an empirical proof of the logically equivalent inequality of household saving and business investment. Allais has definitively settled the IS-debate of the 1930s in 1993. Since then, all models, includung $I S-L M$, that have been built and are still being built on the equality/identity of investment and saving have to be regarded either as limiting cases or as formally deficient. The empirical proof is to be found in national accounting. Reality's signifier is $\Delta Q_{f i} \neq Y_{D}$

\subsection{Raw and cooked transaction recording}

Figure 8 presents an exemplary picture of all market transactions in period $t$ between the household sector and the differentiated business sector. The picture includes investment expenditure and the profit distribution of the two firms. 
Figure 8: Raw Transaction Recording of an Investment Economy with Profit Distribution

\begin{tabular}{|c|c|c|c|c|c|}
\hline \multicolumn{2}{|c|}{ Balancing of the transaction matrix } & $\mathcal{E}_{\mathbf{H}}$ & $\mathcal{E}_{\mathbf{B} C}$ & $\mathcal{E}_{\mathbf{B} I}$ & $\Sigma$ \\
\hline Consumption expenditure & $C$ & -100 & 100 & & 0 \\
\hline Wage income & $Y_{W C}$ & 80 & -80 & & 0 \\
\hline Distributed profit & $Y_{D C}$ & 10 & & & 10 \\
\hline Investment expenditure & $I$ & & & 50 & 50 \\
\hline Wage income & $Y_{W I}$ & 40 & & -40 & 0 \\
\hline Distributed profit & $Y_{D I}$ & 5 & & & 5 \\
\hline Balancing items & $\Delta_{1}$ & $\begin{array}{r}35 \\
\Delta S_{f i}\end{array}$ & $\begin{array}{r}20 \\
\Delta Q_{f i C}\end{array}$ & $\begin{array}{r}10 \\
\Delta Q_{f i I}\end{array}$ & \\
\hline Distributed profit & & & -10 & -5 & -15 \\
\hline Balancing items & $\Delta_{2}$ & $\begin{array}{r}35 \\
\Delta S_{f i}\end{array}$ & $\begin{array}{r}10 \\
\Delta Q_{r e C}\end{array}$ & $\begin{array}{r}5 \\
\Delta Q_{r e I}\end{array}$ & \\
\hline Money/Finance & & & -50 & & -50 \\
\hline Balancing items & $\Delta_{3}$ & 35 & -40 & 5 & $\dashv$ \\
\hline
\end{tabular}

Profits appear in row $\Delta_{1}$. The General Complementarity is recoverable from row $\Delta_{2}$ and column $\Sigma$. Note that the retained profits of both firms are the dependent variables. Row $\Delta_{3}$ shows the flow-of-funds, i.e. the changes of deposits and overdrafts at the central bank and the net financing requirements of the business sector.

It is worth emphasizing that the transaction matrix delivers the limiting case $I=\Delta S_{f i}$, which is so dear to common sense, in row $\Delta_{2}$ only under the condition $Y_{D C}=20$ and $Y_{D I}=10$, that is, if distributed profits happen to be equal to profits in the period under consideration. The 
zero profit case is in turn a special case of the limiting case. It is obvious that no raw transaction matrix ever has nor ever will provide this limiting case.

The crucial characteristic of the derivative Figure 9 is, again, the illegitimate placement of profit among the transactions. A dependent variable tacitly becomes an independent variable.

Figure 9: Cooked Transaction Recording of the Investment Economy (refers to Figure 8)

\begin{tabular}{|c|l|r|r|r|r|}
\cline { 3 - 6 } \multicolumn{2}{l|}{} & $\mathcal{E}_{\mathbf{H}}$ & $\mathcal{E}_{\mathbf{B}}$ & Capital & \multicolumn{1}{c|}{} \\
\hline Consumption expenditure & $C$ & -100 & 100 & & 0 \\
\hline Investment expenditure & $I$ & & 50 & -50 & 0 \\
\hline [GDP (memo)] & & & $\Upsilon$ & & \\
\hline Wage income & $Y_{W}$ & 120 & -120 & & 0 \\
\hline Net profits & & 15 & -30 & 15 & 0 \\
\hline Balancing items & $\Delta_{1}$ & 35 & 0 & -35 & 0 \\
\hline
\end{tabular}

The cooked transactions yield the $G D P$ formula in column $\mathcal{E}_{\mathbf{B}}$ which now reads:

$$
\Upsilon=C+I=Y_{W}+\Delta Q_{f i}
$$

The formula stays the same independently of whether profits are fully distributed or fully retained or something in between. Profit distribution, although a market transaction, is invisible in (28). The black hole effect reappears and this renders the formula worthless for all practical purposes. Nonetheless, the cooked matrix reproduces the net financing requirements of the business sector correctly in row $\Delta_{1}$. This feature explains the comparative success of the accounting approaches in coming to grips with the financial crisis.

\subsection{The Formal Offside Trap and the Turnoff to Verbiage}

Let us suppose somebody looks at the General Complementarity (27), which states that retained profit is equal to the difference of the business sector's investment expenditure and the household 
sector's financial saving, and proposes to refer to the sum of saving and retained profit as total private saving $\Sigma$ because retained profit may, quite commonsensical, be regarded as saving of the business sector (among many others [Godley and Lavoie 2007, p. 37]). Thereby, a new definition, (i) in (29), would be added to the already existing formalism. Together with the General Complementarity (ii) this gives (iii) which states that total private saving $\Sigma$ (and not household sector saving $\Delta S_{f i}$ ) "equals" investment:

$$
\text { (i) } \Sigma \equiv \Delta S_{f i}+\Delta Q_{r e} \quad \text { (ii) } \Delta Q_{r e} \equiv I-\Delta S_{f i} \quad \Rightarrow \quad \text { (iii) } I \equiv \Sigma \quad \mid t \text {. }
$$

We thus arrive at an implicit definition that is no proper definition at all (Stigum 1991, pp. 35-36). Moreover, while the General Complementarity contains valuable information eq. (iii) in (29) is an informational black hole. What went wrong?

The examples in Figure 10 make it clear that the respective definitions in the second row are inadmissible despite the fact that they appear rather commonsensical.

Figure 10: Verbal or Formal Redundancy Violates the Economic Principle and Calls for Occam's Razor

\begin{tabular}{|c|c|c|}
\hline \multirow{2}{*}{ Verbal redundancy } & \multicolumn{2}{|c|}{ Formal redundancy } \\
\cline { 2 - 3 } & $I S$ & $G D P$ \\
\hline Unemployed $\equiv$ all grown-ups - employed & $\Delta Q_{r e} \equiv I-\Delta S_{f i}$ & $\Delta Q_{f i} \equiv C+I-Y_{W}$ \\
\hline Workforce $\equiv$ unemployed + employed & $\Sigma \equiv \Delta Q_{r e}+\Delta S_{f i}$ & $\Upsilon \equiv \Delta Q_{f i}+Y_{W}$ \\
\hline Workforce $\equiv$ all grown-ups & $I \equiv \Sigma$ & $\Upsilon \equiv C+I$ \\
\hline
\end{tabular}

The crucial point is that the respective definitions in themselves are indeed pretty harmless. What makes them unacceptable is that they appear in the wrong place at the wrong time. When the respective definition in the first row has been made, the second definition runs into the offside trap. It is the context that makes all definitions in the second row redundant and therefore unacceptable. In combination with the definitions in the first row they produce the pure verbiage in the third row. Each additional definition has to be consistent with the already existing formalism. This is not the case in (29) and the examples of Figure 10. The sequence of definitions matters. 
The General Complementarity (27) is the logical terminus of the structural axiomatic analysis. Accordingly, there is no such thing as total private saving $\Sigma$ if retained profit of the business sector and saving of the household sector have been defined. Introducing or, for that matter, reiterating the notion of corporate saving in textbooks (Samuelson and Nordhaus 1998, p. 194 ) is redundant from the structural axiomatic viewpoint and clearly at odds with the economic principle. Formal inefficiencies, this goes without saying, are indefensible in economics.

It did not got lost in the extensive discussion of what Keynes really meant that, in fact, investment expenditures might not be equal to household saving and this was explained with the perfect reconcilability of an ex ante disequilibrium with the ex post bookkeeping truism $I \equiv S$, which in turn is different from the equilibrium condition $I=S$. This poor rationalization is sufficient to lay common sense to rest but ultimately does not work for the simple reason that a meticulous recording of all transactions during one period arrives at the General Complementarity. The rest is verbiage.

\section{CONCLUSION}

The accounting approach could be a valuable tool of economic analysis. As things stand at the moment, however, it is formally disabled by cooked transaction recording and redundant definitions. The rectified accounting approach has a critical role to play in the empirical falsification of theoretically indefensible identity assertions. Common sense will eventually come round to the conclusion that investment never was and never will be equal to saving under any description; likewise for the spurious national income identity. To deliver the requisite proofs is the obvious next step for rigorous accountants. 


\section{REFERENCES}

Allais, M. 1993. Les Fondements Comptable de la Macro-Économie (2nd ed.). Paris: Presses Universitaires de France.

Arrow, K. J., and F.H. Hahn. 1991. General Competive Analysis. Amsterdam, New York, NY: North-Holland.

Bezemer, D. J. 2009. "No One Saw This Coming: Understanding Financial Crisis Through Accounting Models." MPRA Paper, 15892, pp. 1-50.

Coates, J. 2007. The Claims of Common Sense. Moore, Wittgenstein, Keynes and the Social Sciences. Cambridge, New York, NY: Cambridge University Press.

Dennis, K. 1982. "Economic Theory and the Problem of Translation (I)." Journal of Economic Issues, 16(3), pp. 691-712.

Desai, M. 2008. "Profit and Profit Theory." in S. N. Durlauf, \& L. E. Blume (Eds.), The New Palgrave Dictionary of Economics Online (2nd ed., pp. 1-11). Houndmills, Basingstoke, UK: Palgrave Macmillan.

Godley, W., and M. Lavoie. 2007. Monetary Economics. An Integrated Approach to Credit, Money, Income and Wealth. Houndmills, Basingstoke,UK: Palgrave Macmillan.

Hahn, F. H. 1980. "General Equilibrium Theory." Public Interest. Special Issue, The Cisis in Economic Theory, pp. 123-138.

1984. Equilibrium and Macroeconomics. Cambridge, MA: MIT Press.

Kakarot-Handtke, E. 2011a. "Primary and Secondary Markets." SSRN Working Paper Series, 1917012, pp. 1-26.

_.2011b. "Reconstructing the Quantity Theory (II)." SSRN Working Paper Series, 1903663, pp. 1-19.

. 2011c. "Squaring the Investment Cycle." SSRN Working Paper Series, 1911796, pp. 1-25.

Keynes, J. M. 1973. The General Theory of Employment Interest and Money. London, Basingstoke: Macmillan.

Lavoie, M. 1992. Foundations of Post-Keynesian Economics. Cheltenham: Edward Elgar.

Mill, J. S. 2004. "On the Definition of Political Economy; and the Method of Investigation Proper to It." in Essays on Some Unsettled Questions of Political Economy (vol. PA 18202, pp. 5-39). Pennsylvania State University Online. . 2006. A System of Logic. Indianapolis, IN: Liberty Fund. 
Redman, D. A. 1997. The Rise of Political Economy as Science. Methodology and the Classical Economists. Cambridge, MA: MIT Press.

Robinson, J. 1956. The Accumulation of Capital. London: Macmillan.

Samuelson, P. A., and W.D. Nordhaus. 1998. Economics (16th ed.). Boston, MA, Burr Ridge, IL, etc.: Irwin, McGraw-Hill.

Schumpeter, J. A. 1994. History of Economic Analysis. New York, NY: Oxford University Press.

Smith, A. 2008. An Inquiry into the Nature and Causes of the Wealth of Nations. Oxford: Oxford University Press.

Stigum, B. P. 1991. Toward a Formal Science of Economics: The Axiomatic Method in Economics and Econometrics. Cambridge, MA: MIT Press.

Suppes, P. 1968. "The Desirability of Formalization in Science." Journal of Philosophy, 65(20), pp. 651-664.

Tómasson, G., and D.J. Bezemer. 2010. "What is the Source of Profit and Interest? A Classical Conundrum Reconsidered." MPRA Paper, 20557, pp. 1-34.

United Nations (Ed.). 2009. System of National Accounts 2008. New York, NY. 